(9) (1) https://creativecommons.org/licenses/by/4.0/

Dossiê: FORMAÇÃO DOCENTE E PRÁTICA PEDAGÓGICA - TEMPOS, TENSÕES E INVENÇÕES

\title{
PRÁTICA DE DOCÊNCIA EM HISTÓRIA EM TEMPOS DE PANDEMIA: PERCEPÇÕES DE LICENCIANDOS/AS
}

\author{
NADIA GAIOFATTO GONÇALVES ${ }^{1}$ \\ ORCID: https://orcid.org/0000-0002-9375-8659 \\ ANA CLÁUDIA URBAN ${ }^{2}$ \\ ORCID: https://orcid.org/0000-0001-9957-8838
}

\begin{abstract}
RESUMO: O objetivo deste artigo é refletirmos sobre o ensino de História a partir da experiência realizada junto a estudantes do curso de Graduação em História/UFPR durante o desenvolvimento da disciplina Prática de Docência no ano letivo de 2020. Como parte das atividades da referida disciplina estava o acompanhamento de aulas remotas ofertadas pela Secretaria de Estado da Educação do Paraná (SEED-PR) e a sistematização de registros por meio do diário de campo. Para as reflexões deste artigo abordaremos as observações feitas pelos/as próprios/as licenciandos/as acerca de aulas remotas voltadas para os Anos Finais do Ensino Fundamental e para o Ensino Médio. A partir desse material, aqui assumido como fonte, pretendemos discutir as percepções dos/as licenciados/as sobre a relação ensino aprendizagem, considerando o debate metodológico presente nas aulas acompanhadas. Como resultado apontamos a presença do dilema quantidade x qualidade (aprofundamento, problematização) de conteúdo; a forma de mediar o conhecimento acadêmico e o conhecimento histórico escolar e a característica mnemônica das atividades propostas nas aulas remotas, em detrimento de problematizações que consideram a argumentação dos alunos ao se relacionarem com o conhecimento histórico. Para a análise destas questões utilizamos como referência as contribuições de Pierre Bourdieu, em especial os conceitos de habitus e de campo, as do campo da Educação Histórica com Jörn Rüsen, para refletir sobre a formação da consciência histórica e as de Ana Zavala, para pensar a prática docente e o sentido destas observações na formação inicial de professores de História.
\end{abstract}

Palavras-chave: formação de professores, ensino de História, prática de docência.

\section{TEACHING PRACTICE IN HISTORY IN PANDEMIC TIMES: PERCEPTIONS FROM LICENSORS}

\begin{abstract}
The objective of this article is to reflect on the teaching of History from the experience carried out with academics of the Undergraduate Course in History/UFPR during the development of the Teaching Practice course in the academic year of 2020. As a part of the activities of that course, monitoring of remote classes was offered by the State Department of Education of Paraná as well as the systematization of records through the field diary. For the reflections of this article, we will approach the observations made by the licensors themselves about remote classes focused on the Final Years of

\footnotetext{
${ }^{1}$ Docente do Departamento de Teoria e Prática de Ensino - Setor de Educação - UFPR. Curitiba, PR, Brasil. nadiagg@ufpr.br

2 Docente do Departamento de Teoria e Prática de Ensino - Setor de Educação - UFPR. Curitiba, PR, Brasil. claudiaurban@uol.com.br
} 
Elementary School and for High School. From this material, here understood as a source, we intend to discuss the graduates' perceptions about the teaching-learning process, considering the methodological debate present in the classes that were observed. As a result, we point out the presence of the quantity $\mathrm{x}$ quality dilemma (deepening, problematization) of content; the way of mediating academic knowledge and historical school knowledge and the mnemonic characteristic of the activities proposed in remote classes, to the detriment of problematizations that consider licensors' arguments when relating to historical knowledge. For the analysis of these questions, we used as a reference the contributions of Bourdieu, especially the concepts of habitus and field, those of the field of Historical Education with Rüsen, to reflect on the formation of historical consciousness and those of Zavala, to think the teaching practice and the meaning of these observations in the initial formation of History teachers.

Keywords: teacher training, history teaching, teaching practice.

\section{LA PRÁCTICA DOCENTE EN EL AREA DE HISTORIA EN TIEMPOS DE PANDEMIA: PERCEPCIONES DE LOS LICENCIANDOS}

RESÚMEN: El objetivo de este artículo es reflexionar sobre la docencia de la História a partir de la experiencia realizada con académicos de la Licenciatura en Historia/UFPR durante el desarrollo de la disciplina Práctica Docente en el año académico 2020. Formaba parte de las actividades de esa disciplina la asistencia a las clases remotas que ofrece la Secretaría de Educación del Estado de Paraná y la sistematización de registros a través del diario de campo. Para las reflexiones de este artículo, nos acercaremos a las observaciones realizadas por los propios licenciandos sobre las clases remotas enfocadas a los últimos años de la educación secundária y Bachillerato. A partir de este material, asumido aquí como fuente, pretendemos discutir las percepciones de los licenciados sobre la relación enseñanzaaprendizaje, considerando el debate metodológico presente en las clases asistidas. Como resultado, señalamos la presencia del dilema cantidad x calidad (profundización, problematización) de los contenidos; la forma de mediar el conocimiento académico y el conocimiento histórico escolar y la característica mnemotécnica de las actividades propuestas en las clases remotas, en detrimento de las problematizaciones que consideran los argumentos de los licenciandos al relacionarse con el conocimiento histórico. Para el análisis de estas cuestiones utilizamos como referencia los aportes de Bourdieu, especialmente los conceptos de habitus y campo, los del campo de la Educación Histórica con Rüsen, para reflexionar sobre la formación de la conciencia histórica y los de Zavala, pensar la práctica docente y el significado de estas observaciones en la formación inicial de los profesores.

Palabras clave: formación del profesorado, enseñanza de la historia, práctica docente. 


\section{INTRODUÇÃO}

A formação de professores/as historicamente vem enfrentando desafios recorrentes que, por vezes, são reconfigurados diante de demandas específicas. A pandemia de Covid-19 trouxe novos elementos para essa discussão, além de outros que foram agravados. Como abordado por Macedo (2021), para o campo educacional, a desigualdade que marca as escolas públicas e o perfil de docentes e discentes delas, foi potencializada pela pandemia, em seus desdobramentos em desigualdades sociais, educacionais, e também digitais, sendo necessário retomar, como propõe a autora, a discussão sobre se a educação neste contexto, continua sendo um direito, ou pode ser considerada um privilégio.

$\mathrm{Na}$ nossa instituição, podemos identificar que também houve impactos. Em pesquisa realizada pela Pró-Reitoria de Graduação ${ }^{3}$, sobre o Ensino Remoto Emergencial (ERE) em que cerca de $20 \%$ dos/as estudantes de graduação responderam (a resposta era voluntária), estes indicaram " $89,6 \%$ (x estudantes) relataram ter se matriculado e cursado ao menos uma disciplina na modalidade ERE, enquanto o $10,5 \%$ não cursou por não ter se matriculado $(7,9 \%)$ ou por ter cancelado a matrícula antes mesmo de cursar (2,6\%)" (p.40). Ainda, das razões para aqueles que não cursaram disciplinas nesta modalidade, estão desde a falta de oferta de disciplina (opcional para docentes no primeiro momento) $(27,5 \%)$, não ter conseguido vaga (19,5\%), a dificuldades pessoais, de ambiente (cerca de $30 \%$ ), e apenas $2,1 \%$ indicou que não tinha equipamentos (p.41).

Sobre estes dados, podemos ponderar tanto a baixa porcentagem de respondentes, quanto o fato de a pesquisa ter sido divulgada e respondida on-line; assim como, o fato de os resultados estarem agregados sem identificação das respostas por curso. Além disso, um número significativo, mas ignorado, de estudantes sem equipamento ou acesso à internet, não responderam por falta de informação da existência da pesquisa, ou mesmo por não ter como respondê-la. Porém, é preciso destacar que houve mais de um edital institucional para empréstimo de equipamentos para estudantes que necessitassem. Por enquanto não há dados suficientes para afirmar de que forma eles foram impactados, mas é plausível a hipótese de que também no ensino superior, as desigualdades sociais, educacionais e digitais afetaram os estudos desses/as graduandos/as.

Neste contexto de pandemia e de ensino remoto, com as escolas públicas fechadas presencialmente, a questão da prática de docência - aqui assumida como sinônima para estágio despontou como um desafio para as licenciaturas, com respostas as mais diversas, desde a suspensão da disciplina e das atividades a ela relacionadas, até a busca de alternativas que permitissem sua continuidade, dentro das possibilidades não presenciais.

Neste artigo, abordaremos a formação de licenciandos/as em História, na Universidade Federal do Paraná (UFPR) quanto a uma das atividades que foram desenvolvidas de forma remota na disciplina de Prática de Docência em História, em 2020. Na versão presencial, a ementa da referida disciplina é constituída de três eixos principais: observação, planejamento e regência. Aspectos estes que marcam a dinâmica das ações que envolvem a relação entre o/a acadêmico/a em fase de formação e as escolas de Educação Básica. Aqui trataremos apenas da primeira etapa das atividades da disciplina, que é a de observação, embora os/as licenciandos/as tenham, posteriormente,desenvolvido as demais etapas.

No início do período da pandemia, o calendário letivo da UFPR foi suspenso a partir de 17 de março. Em seguida, foi editada a Resolução 42/2020-CEPE ${ }^{4}$, que previa a possibilidade da realização de atividades de estágio e da prática de docência de forma remota. Desta forma, foi estabelecida a opção para os/as docentes de ofertarem essas disciplinas e, também, a opção de os/as discentes aderirem ou não, uma vez que o calendário estava suspenso.

\footnotetext{
3 Disponivel em http://www.prograd.ufpr.br/portal/wp-content/uploads/2020/10/Periodo-Especial-Junho-Outubro2020_ERE1_Pesquisa_RelatorioFinal1.pdf?fbclid=IwAR2kcHfJuNmpdRTyc3B_qgGTsCgyWlFUTnkikGG6mI0gTAPsALA-fBtedGA

4 Disponível em http://www.soc.ufpr.br/portal/wp-content/uploads/2020/05/RESOLU\%C3\%87\%C3\%83ON\%C2\%BA-42-2020-CEPE.pdf 
Como a Secretaria de Estado de Educação do Paraná (SEED) iniciou a disponibilização de aulas por meio de canal do Youtube ${ }^{5}$, propusemos uma primeira etapa de atividade remotas. Com o limite de não haver interação do professor, nas aulas da SEED, com estudantes da educação básica (Fundamental II e Ensino Médio), seria possível que os/as licenciandos/as observassem elementos como escolhas didáticas, problematização do tema, diálogo com a historiografia, vocabulário utilizado, atividades propostas, entre outros.

Formalizamos a proposta junto ao Departamento e ao Colegiado do Curso, e sendo aprovada, consultamos os/as licenciandos/as matriculados/as na disciplina. Oportunamente foi debatido sobre a adesão à proposta, que era de fato uma opção. Assim, quem optasse por não realizar a atividade teria, ao retorno do calendário letivo, o direito de desenvolver as atividades relacionadas à disciplina. Houve um considerável aceite por parte dos/as acadêmicos/as, com 32 participantes dentre 39 matriculados.

Esta etapa aconteceu no período compreendido entre 19 de maio a 21 de julho, com um cronograma pré-estabelecido para acompanhamento das atividades, incluindo reuniões gerais com as três turmas, bem como atendimento individualizado. Para registro das observações foi utilizado o diário de campo (OLIVEIRA, 2009) tal como faríamos na prática de docência presencial. Com esta escolha metodológica, os/as acadêmicos/as deveriam registrar suas observações em relação às aulas e, ao final de um bloco de exposições observadas, sistematizar uma reflexão, considerando sempre que a natureza das aulas não permitia interação, desta forma a intenção residia na análise dos conteúdos, estrutura da aula, atividades propostas, entre outros aspectos. Os encontros entre acadêmicos/as e professoras da disciplina de Prática de Docência aconteciam com regularidade e, eram permeados por reflexões registradas no diário. As anotações destes diários de campo são nossa fonte principal, abordados na sequência deste artigo.

O critério para a escolha de quais diários seriam contemplados aqui foi o de trazermos trechos que de alguma forma fossem representativos acerca de questões recorrentes nas observações registradas pelos/as licenciandos/as, com uma boa qualidade de síntese e de crítica, de forma a otimizar as reflexões sobre as questões por eles mencionadas. Assim, evitamos citar aqui diários de outros/as licenciandos/as que, embora tenham tratado dos mesmos elementos, por vezes não o fizeram de maneira sistematizada, ou o fizeram apenas por meio de descrição.

Também, optamos por trazer o link das aulas que são mencionadas nas citações, por duas razões: permitir que os/as leitores/as do artigo possam acessá-las e avaliar ou compreender as observações registradas, e porque elas são públicas e acessíveis, não havendo necessidade de autorização para esta menção. Não intentamos aqui nenhum julgamento sobre os/as docentes, assumundo que as aulas assistidas, e agora disponíveis para o público, são fontes para o debate e reflexões sobre o ensino de História, por isso igualmente buscamos permitir aos/às leitores/as que visualizassem as aulas observadas.

Como referenciais importantes para pensarmos essa formação, e particularmente essa experiência - que foi também para nós, como docentes, de muito aprendizado - destacamos os conceitos de habitus e de campo, de Pierre Bourdieu. Para o autor, o habitus pode ser compreendido como o conjunto

[...] de disposições adquiridas pela experiência, logo, variáveis segundo o lugar e o momento. [...] Sendo produto da incorporação da necessidade objetiva, o babitus, necessidade tornada virtude, produz estratégias que, embora não sejam produto de uma aspiração consciente de fins explicitamente colocados a partir de um conhecimento adequado das condições objetivas, nem de uma determinação mecânica de causas, mostram-se objetivamente ajustadas à situação. [...] [Os agentes] fazem, com muito mais freqüência do que se agissem ao acaso, "a única coisa a fazer". Isso porque, abandonando-se às intuições de um "senso prático" que é produto da exposição continuada a condições semelhantes àquelas em que estão colocados, eles antecipam a necessidade imanente ao fluxo do mundo (BOURDIEU, 2004, p. 21-23).

Desta forma, tal discussão nos auxilia a pensar de que forma a trajetória pessoal - e as crenças, valores, representações, neste caso, o ensino de História, sobre ser professor, entre outros - configuram escolhas na prática, inclusive profissional, como parte do babitus (GONÇALVES, 2012). Tanto por parte

\footnotetext{
${ }^{5}$ Canal Aula Paraná - https://www.youtube.com/channel/UCfbFento2_mCEyUgeiwImiQ
} Educação em Revista|Belo Horizonte|v.37|e32626|2021 
de nossos/as licenciandos/as, professores/as em formação, quanto dos/as docentes cujas aulas foram assistidas.

Muito articulado ao habitus, o conceito de campo, como espaço social em que os agentes interagem - e se estabelecem e disputam por normas e capitais diversos - nos lembra das configurações que são construídas social e historicamente, com as quais os/as agentes, com seu habitus específico, interagem (BOURDIEU, 1996). A escola, a cultura escolar, o currículo, o livro didático, a sala de aula, até o ensinar História, são assim permeados por elementos que estão para além do que cada agente particularmente pode pensar, e ele/a terá que lidar com essas demandas, com essas tradições ou convenções, em um processo contínuo de disputas, enfrentamentos e acomodações.

Embora saibamos da existência de habitus dos/as licenciandos/as e dos/as docentes das Aulas Paraná, não é nossa intenção abordá-lo no sentido das particularidades deles, mas para identificar expressões desse habitus em relação à forma como as aulas de História são organizadas e ministradas (escolhas, estratégias didáticas, referenciais, abordagem dos temas, entre outros), e em como são percebidas, em suas positividades e limitações, por parte dos/as estudantes que as estavam observando e analisando. Ou seja, de que forma ele se manifesta nas práticas dos/as docentes (como o senso prático mencionado por Bourdieu), bem como nas representações e expectativas dos/as estudantes, a partir das discussões teórico-metodológicas abordadas nas disciplinas de teor pedagógico do curso.

Tratando especificamente da formação de professores de História, podemos compreender a consciência histórica e sua formação como parte inerente ao babitus, e profundamente necessária para este/a docente, até porque suas aulas - e todas as escolhas que elas envolvem - serão permeadas por essa consciência, e numa situação ideal, com a finalidade de desenvolver uma aprendizagem histórica fundamentada, reflexiva e crítica.

Rüsen (2010) compreende a consciência histórica como "uma categoria geral que não apenas tem relação com o aprendizado e o ensino de história, mas cobre todas as formas de pensamento histórico; através dela se experiencia o passado e se o interpreta como história" (RÜSEN, 2010, p. 36). $\mathrm{O}$ autor destaca três pontos principais acerca dela:

\footnotetext{
Primeiro, a consciência histórica não pode ser meramente equacionada como simples conhecimento do passado. A consciência histórica dá estrutura ao conhecimento histórico como um meio de entender o tempo presente e antecipar o futuro. (...)

Segundo, a consciência histórica pode ser analisada como um conjunto coerente de operações mentais que definem a peculiaridade do pensamento histórico e a função que ele exerce na cultura humana. (...)

Terceiro, através da análise das operações da consciência histórica e das funções que ela cumpre, isto é, pela orientação da vida através da estrutura do tempo, a didática da história pode trazer novos insights para o papel do conhecimento histórico e seu crescimento na vida prática (RÜSEN, 2010, p. 36-38, grifo nosso).
}

A partir da compreensão deste conceito, e da forma como ele permeia e orienta a finalidade do ensino de História, entendemos que na observação das práticas de outros/as docentes, os/as licenciandos/as podem melhor compreender algumas escolhas didáticas feitas, bem como seus limites e potencialidades para o desenvolvimento desta consciência histórica, ao mesmo tempo em que percebem elementos do habitus e a força de convenções do campo sobre esta ação docente.

Por fim, a reflexão de Zavala (2017) nos auxilia em relação à representação sobre o que é um bom professor, como ela é construída - no habitus, nos campos, como a academia - e no que compreendemos como um/a bom/a professor/a de História, com as especificidades epistemológicas da História. Necessariamente, esta representação, que cada licenciando/a tem, aparece na expectativa ao assistir as aulas da SEED e na análise que faz acerca das práticas observadas. Bem como, pode impactar na forma como se veem ou esperam "ser formados", para conseguirem colocar em prática esse ideal de docência. Para a autora,

Está claro que cuando uno se inscribe en una institución de formación profesional (ya sea el instituto de profesores o la facultad de medicina) tiene ya alguna idea de lo que hará cuando ejerza la profesión. Sin embargo, tratándose de la formación profesional docente hay algunas Educação em Revista|Belo Horizonte|v.37|e32626|2021 
consideraciones que podrían tener su relevancia. De hecho sucede que a diferencia del caso de otras profesiones todo el mundo ha estado frente a una enorme diversidad de profesionales de la enseñanza prácticamente a lo largo de toda su vida, o por lo menos en los últimos 15 años antes de inscribirse en la carrera (y a veces más, porque no todos lo hacen al egresar de la secundaria) conviviendo pasivamente con el ejercicio de la profesión que ha elegido. También está claro que cuando alguien se inscribe en una institución de formación docente -como en cualquier curso o carrera- no espera salir igual que como entró. Lo que no está tan claro es que -una vez en el ejercicio de la profesión- todos se sientan llamados a cambiar lo que hacen, en el entendido de que encuentren razones para hacerlo. Tampoco está claro que, desde un mundo exterior a las prácticas, se puedan apreciar los múltiples y diversos procesos de cambio que se producen en el lecho del río. (ZAVALA, 2017, p.728)

Neste sentido, podemos compreender a importância desta formação, em seu conjunto, com a finalidade de subsidiar, de maneira fundamentada, reflexões que possam esclarecer, orientar e auxiliar a esses/as licenciandos/as a pensarem a respeito do que é ser professor/a, sem ilusões acerca de uma absoluta autonomia e independência em sala de aula e na escola - uma vez que há configurações externas, do campo, de normativas, entre outras - mas, também, que lhes permita perceber as possibilidades, o sentido e a relevância de uma prática que efetivamente contribua, no caso da nossa disciplina, para a formação de uma consciência histórica mais elaborada, fundamentada e crítica, tão necessária para o exercício de uma cidadania com viés humanista.

\section{TEMAS DAS AULAS E ABORDAGENS DOS CONTEÚdOS NAS AULAS PARANÁ}

Considerando que as aulas disponibilizadas pela SEED abrangiam do $6^{\circ}$ ano do Ensino Fundamental até o $3^{\circ}$ ano do Ensino Médio, avaliamos, junto aos/às acadêmicos/as, a possibilidade de acompanharem diversas aulas e escolherem o ano da escolarização que mais lhes interessavam, o conteúdo abordado em determinado ano, uma sequência de aulas ou ainda o ano correspondente ao início das observações, tendo em vista que alguns/as acadêmicos/as já haviam iniciado as atividades no espaço escolar.

O primeiro elemento que destacamos, presente nos diários de campo, foi a percepção dos/das licenciandos/as em relação à permanência de uma organização cronológica e linear dos conteúdos e, mais do que isso, de uma abordagem em geral tradicional, informativa e pouco problematizada. O exemplo abaixo, relativo a uma aula para o $9^{\circ}$ ano, com o tema Primeira República ${ }^{6}$, é bastante representativo e traz questões que foram recorrentes na fala de outros/as acadêmicos/as. Mantivemos a citação na íntegra, tanto para trazer uma ideia sobre a forma dos diários, como para permitir visualizar o conjunto das observações quanto a esta aula.

A professora inicia a aula apresentando brevemente o conteúdo, explicando os múltiplos nomes dados à Primeira República e enfatizando muito suas periodizações (República da Espada 18891894 e República Oligárquica 1894-1930). Logo no início ela faz menção ao Governo Vargas e à criação do nome República Velha, porém não aprofunda o assunto.

A aula se aprofunda a partir da projeção do livro didático, com a primeira página do capítulo correspondente e uma imagem sobre candidatos políticos. A professora procura estabelecer um paralelo com o presente, perguntando aos alunos se conseguem identificar semelhanças entre as formas de conseguir eleitores nos dois períodos de tempo. Pede então que os alunos respondam as perguntas do livro para que o professor corrija na volta às aulas presenciais. Essa aproximação, então, fica por conta dos alunos já que a professora não problematiza o assunto e segue com a aula.

A aula é focada no segundo período apresentado pela professora, a República Oligárquica. Por isso, ela passa um tempo significativo explicando denominações e conceitos ligados à política, oligarquia, coronelismo, o sistema eleitoral e seus diversos personagens e situações. Apesar da linguagem ser mais científica em boa parte da aula, a professora aproxima seus antigos alunos e aqueles que estão assistindo a aula através de dúvidas frequentes ("Daí, muitos dos meus alunos

\footnotetext{
6 Esta aula está disponível em https://www.youtube.com/watch?v=3wVYeV7b4oM\&list=PLnGI1S4A8rusWZo8V ZgwF7eE0-03PlT\&index $=2 \& \mathrm{t}=0 \mathrm{~s}$ 
perguntam e eu garanto que você deve estar com a mesma dúvida[...]"), deixando a aula parecendo uma conversa em certos momentos.

Ao apresentar a política do café com leite, a professora tenta problematizar o nome e o conceito, porém isso é feito de maneira rápida, sem mostrar quais são os historiadores que defendem e divergem acerca do nome, e não parece ter qualquer importância no conteúdo final. A explicação do que foi a política toma a maior parte do tempo. Por algum motivo, esse é o único ponto que ela retoma o que havia falado, resumindo e frisando o porquê do café com leite.

Rapidamente, a partir de uma tabela, a professora procura relacionar a Primeira República com a industrialização e a modernização do Brasil. Ela projeta duas perguntas que responde logo depois, sem estimular uma reflexão sobre. O processo de urbanização é mais explicado que os outros dois, e a foto escolhida para isso é melhor utilizada que a tabela anterior. Com a urbanização, a professora foi capaz de estabelecer melhor uma construção do conhecimento, encadeando os eventos, ao invés de simplesmente ditar o conteúdo como fez em boa parte da aula. Sobre esse tema, ela procura aproximar o conteúdo com o aluno ao pedir uma pesquisa sobre os processos de modernização e urbanização no local onde o mesmo mora.

A imigração é abordada de forma ainda mais rápida, com foco nas motivações dela e com menção superficial sobre suas consequências. Ela apresenta e explica um quadro sobre a busca do branqueamento no Brasil e um gráfico sobre o aumento da imigração.

É uma aula em grande parte expositiva, sem muitas reflexões ou estímulo aos alunos, e claramente organizada em tópicos (Dimensão política, econômica e social, com poucas relações entre si).

Charges, gráficos e slides explicativos são o principal apoio para a explicação da professora, porém não são tratados como fontes históricas ou mesmo colocados em primeiro plano na explicação. São só recursos visuais para os alunos, algumas vezes rapidamente explicados. Ela dedica diversos minutos para quizzes de perguntas objetivas e logo depois mais perguntas subjetivas. [Em] Algumas perguntas a correção é novamente deixada para as aulas presenciais, e outras (poucas) ela dá a resposta. As perguntas são só projetadas, sem explicações ou problematizações sobre elas. Uma das perguntas é sobre a Constituição de 1891, que não foi abordada em momento nenhum na aula.

De maneira geral, a aula foi executada muito rapidamente e superficialmente em relação ao conteúdo. Não sei se isso ocorreu por se tratar do ensino fundamental ou porque só poderia tratar do conteúdo em uma aula, porém não foi uma explicação suficiente ou instigante considerando o assunto. Não houve problematizações ou incentivo para que os alunos pensem sobre o que está sendo apresentado, os apoios foram utilizados como simples ilustração e as aproximações com a realidade do aluno ficaram inteiramente por conta deles. (Licencianda 1).

Aqui destacamos questões sobre a percepção da licencianda acerca da aula assistida:

- A dimensão linear e cronológica, pouco ou superficialmente explicada em relação às interrelações entre as dimensões políticas, econômicas e sociais;

- A ausência da dimensão simultaneidade (seja no que estava acontecendo fora do Brasil, seja com um contexto mais regional, no Paraná, já que estas aulas, diferente da sala de aula presencial, têm como público estudantes de todo o Estado);

- Uma certa superficialidade na abordagem de conceitos;

- Pouco ou nenhum diálogo explícito com a historiografia;

- Uso somente ilustrativo de fontes históricas;

- Abordagem com pressa do conteúdo (muito conteúdo concentrado), com pouco espaço para aprofundar problematizações, incluindo a relação com o presente;

- Atividades propostas, mas não explicadas ou abordadas. Sobre os exercícios, os abordaremos no próximo tópico do artigo.

Em primeiro lugar, é importante pensarmos a representação de uma boa aula de História e de um/a bom/a professor/a de História, que acaba por surgir destas observações. Como grande parte da turma, esta estudante não realizou prática de docência presencial, pois a situação de pandemia impediu sua presença no espaço escolar. Não tendo realizado atividade de docência até este momento, a ideia de uma aula de História na educação básica parece estar bastante idealizada, uma vez que as referências que a estudante tem, além daquelas de sua própria trajetória enquanto aluna da educação básica, mais distantes, são as aulas na Universidade. Ou seja, aulas em que a dimensão conceitual, as inter-relações de diferentes âmbitos, as referências e as fontes, devem ser abordadas de forma mais fundamentada e 
problematizada possível. A própria matriz curricular permite isso, pois cada disciplina que trata de contextos ou temas históricos é focada em um tema ou recorte específico, que o/a docente, em geral, pesquisa e é especialista. Desta maneira, o aprofundamento na abordagem, o vocabulário, e outros, é mais aprofundado e preciso.

Aqui lembramos de uma questão recorrente nas discussões sobre formação de professores, qual seja, como o currículo da graduação ainda possuir resquícios do modelo $3+1$, em uma separação ou no mínimo, disputas - entre conteúdos e pesquisas historiográficas (o que) e a dimensão pedagógica e as pesquisas a ela relacionadas (porquê, para quê, para quem, como ensinar) (GONÇALVES e MONTEIRO, 2017).

$\mathrm{Na}$ graduação no ensino superior, é comum que o tema da disciplina seja ensinado sob perspectiva historiográfica, mas sem que seja incluída alguma reflexão sobre sua presença no currículo da Educação Básica, em livros didáticos, ou mesmo, sobre as possibilidades de abordagem do tema no Ensino Fundamental e Médio. Questão esta que envolve disputas de campos, já tratadas por autores como Martins (2002), Mesquita (2008) e Cerri (2018), neste lugar de fronteira que é o ensino de História (MONTEIRO e PENNA, 2011) e que está voltando à tona com força, mediante a aprovação da Base Nacional Comum de Formação de Professores (BNCFP) (BRASIL, 2019).

No caso da abordagem mais linear e tradicional, podemos pensar como também está vinculada a disputas sobre o currículo, ainda quadripartite e eurocêntrico (embora o tema da aula em debate seja Brasil), questões essas que também foram recentemente alvo de problematizações, na discussão da Base Nacional Comum Curricular (BNCC) de História (MORENO, 2016), cuja primeira versão buscava romper com este modelo e foi fortemente combatida e questionada. Ao final, a BNCC aprovada (BRASIL, 2017) pode ser compreendida como conservadora em relação aos conteúdos e sua organização, em um movimento de certa acomodação quanto ao que historicamente já estava consolidado em currículos de graduação, da educação básica, no senso comum, nos livros didáticos, na cultura escolar e no babitus de boa parte dos/as agentes envolvidos/as nesta discussão, embora com questões bastante problematizadas no âmbito acadêmico.

$\mathrm{Na}$ observação das aulas, essa questão do currículo foi recorrente, associada a um dilema que não é só do ensino de História: a quantidade x qualidade dos conteúdos a serem ensinados, que tem reflexo no nível de aprofundamento, de tempo e de problematização dos temas e contextos históricos. O conteúdo da educação básica para História vai desde os povos ágrafos, até a eleição do atual presidente, o que vai sempre sendo estendido, associado a novos temas que vão sendo inseridos no período temporal já consolidado. Este é um dos vários dilemas da prática docente discutidos por Lourencetti e Mizukami (2002), sendo que, de certa forma, está associado a outros problemas identificados pela licencianda, como o não aprofundamento sobre o contexto (abordagem mais informativa), das inter-relações entre distintos âmbitos, dos conceitos relacionados, e mesmo, acerca das fontes utilizadas, uma vez que estas acabam sendo mais ilustrações do que, de fato, problematizadas como fontes. Como mencionamos, essas características estavam, de forma recorrente, presentes nas anotações dos diários de campo.

Sobre uma aula para o $9^{\circ}$ ano, continuidade desta primeira, mas com foco nas Revoltas do período ${ }^{7}$, outro discente comenta:

Faltou uma contextualização das revoltas, a professora não conecta os assuntos com a periodização e os conceitos apresentados na aula anterior. Por que estudar as revoltas? Como elas se encaixam no contexto brasileiro, o que as conecta? Não há uma discussão conceitual sobre revolta, e a professora até utiliza o conceito de revolução para falar de Canudos.

Apesar de utilizar fontes (ainda predominantemente ilustrativas), poderia ter explorado as fontes literárias. Poderia ter iniciado o tema da revolta de Canudos com um trecho da obra clássica "Os Sertões", de Euclides da Cunha. Seria uma forma de conectar a obra, o autor, e a história de Canudos com o contexto político brasileiro mais amplo.

Um exemplo da dificuldade de atribuir sentido ao estudo dos temas, está a Revolta da Chibata e que a professora afirma: "é relevante para concluirmos essa 'fase as revoltas". Nem mesmo a professora estabelece uma pista do sentido histórico que pode ser atribuído a essa revolta, poderia ser resolvido por uma discussão conceitual sobre o que é revolta no contexto estudado.

\footnotetext{
7 Aula disponível em https://www.youtube.com/watch?v=ZU0L0yF80cA\&list=PLnGI1S4-A8rusWZo8V ZgwF7eE0$\underline{03 P l T \& \text { index }=2}$
} 
A aula é, no geral, uma compilação de fatos desconexos e não problematizados nem mesmo superficialmente. (Licenciando 2)

Neste caso, é possível observar uma certa escolha, ou dificuldade, na dimensão contextual e conceitual, além da abordagem factual de conteúdo, sem que se busque um sentido explicativo, muitas vezes dando a impressão do conteúdo pelo conteúdo, ou seja, que é abordado porque está na diretriz curricular ou no livro didático, mas sem um sentido mais elaborado. Este tipo de situação também é identificado em exposições de outros/as docentes.

A respeito de uma aula com o tema Revolução Industrial, para o $8^{\circ}$ ano $^{8}$, a licencianda comenta:

Sempre que a professora fala "Revolução Industrial" ela diz que é a primeira, mas ela não chega nem a comentar que vão acontecer outras revoluções desse tipo, o que eu acredito que pode confundir alguns alunos. Novos conceitos são explicados, mas nunca problematizados. [...]

Estou começando a achar que os meus comentários estão sendo sempre os mesmos. Mas isso está acontecendo porque todas as aulas por enquanto seguem a mesma linha: explicações simplistas e breves, sem problematização, atividades fáceis que não gerem reflexão, uma linguagem apropriada a idade dos alunos por parte dos professores, eles só usam o recurso de slides, raramente o livro didático, e há pouquíssimo uso de fontes; só é mostrado imagens, que não são usadas para construir o conhecimento junto ao aluno, apenas são apresentadas. (Licencianda 3)

Esta era a quinta aula assistida pela licencianda, envolvendo dois docentes diferentes. Porém, as aulas do outro professor foram consideradas melhores em alguns aspectos, como no caso desta exemplificada a seguir, cujo tema era Revoluções na Inglaterra - séculos XVI e XVII:

Antes de começar o assunto em si, o professor faz uma diferenciação entre Inglaterra, Grã Bretanha e Reino Unido, deixando, assim, mais fácil para o aluno se localizar geograficamente e deixando claro que a aula seria especificamente sobre a Inglaterra, mostrando o mapa do país e onde ela se localiza no mundo. [...]

Enfim, o professor começa a falar sobre o século XVI e mostra uma imagem da monarca da época, Elizabeth I, e menciona que as suas roupas eram uma forma de demonstração de poder. Mais uma vez, ele fala sobre aspectos do presente, lembrando que atualmente a rainha da Inglaterra é a Elizabeth II. Novamente, o professor relembra os alunos sobre um conteúdo do ano anterior - Henrique VIII, pai de Elizabeth I, e as reformas religiosas.

O professor menciona as políticas mercantilistas da época e faz uma analogia com Brasil e Portugal em relação ao Pacto Colonial, relembrando os alunos o que eles aprenderam no $7^{\circ}$ ano. Mais conceitos são apresentados, como burguesia, nobreza rural (gentry) e pequenos proprietários rurais (yeomen), piratas e corsários (mais uma vez, o professor apresenta exemplos do cotidiano dos alunos para explicar e diferenciar esses termos). O próximo tema abordado é o cercamento e as mudanças sociais que isso trouxe. [...]

A linguagem do professor é bastante coloquial, sendo de fácil entendimento para os alunos. Para ajudar em suas explicações, ele usa slides, que contêm imagens relacionadas ao conteúdo. Achei tudo bem explicado, apesar do professor não fazer nenhum tipo de problematização sobre o que ele estava ensinando. Nenhum tipo de fonte é utilizado na explicação e também não há interdisciplinaridade. (Licencianda 3)

Assim, observamos que, na percepção da acadêmica, este professor demonstra maior conhecimento sobre o tema, fazendo inter-relações com o presente e com conteúdo de anos anteriores, explicando conceitos e buscando ilustrá-los com situações mais familiares aos alunos, em uma linguagem acessível. Porém, a questão da pouca problematização e o uso de fontes como ilustração ainda permanece.

8 Aula disponível em https://www.youtube.com/watch?v $=$ mWOaCWgPOqc\&list=PLnGI1S4A8ruiqiAoN66GfhDhpTuofEH2\&index $=5$

${ }_{9}$ Aula disponível em https://www.youtube.com/watch?v=42YcDAQ9Ufk\&list=PLnGI1S4A8ruiqiAoN66GfhDhpTuofEH2 
Em outras anotações são destacadas diversas características positivas, mas sempre ponderadas, aos olhos dos/as licenciandos/as, sobre o que poderia ter sido melhor. No caso desta aula para o $3^{\circ}$ ano do Ensino Médio, com o tema Urbanização e Industrialização na $1^{a}$ República ${ }^{10}$, o discente destaca:

\begin{abstract}
Quanto ao conteúdo, apesar de um pouco raso, a professora articula bem o contexto brasileiro com o contexto global ( $2^{a}$ Revolução Industrial). Faz um bom uso dos conceitos, explicando-os, e aponta uma análise processual (usa o conceito de longa duração). Um exemplo é a abordagem da escravidão, que apesar de abolida em 1888, teve consequências que não se extinguiram com ela; a professora aponta muito bem a relação da abolição com a urbanização e o lugar do negro nessas sociedades urbanas. Não aprofunda as questões da imigração com a industrialização e o movimento operário.

Quando a professora questiona o motivo de se estudar os processos históricos (busca por sentido histórico ao conteúdo), ela apela para a noção de história "mestra da vida" - a história forneceria exemplos e "erros" que podem ser evitados no presente. Apesar do caráter "exemplar" da história não ser completamente errôneo, é insuficiente e não foge ao lugar comum, o que parece insuficiente para a atribuição de sentido (questões levantadas no último comentário). (Licenciando 2)
\end{abstract}

Neste caso, aparece de forma explícita o sentido para que se aprenda História, em uma explicação hoje compreendida como superada, pois conforme a maneira como é apresentada, pode reforçar a ideia de História cíclica. Porém, precisamos ponderar que, na perspectiva da consciência bistórica e da relação entre passado, presente e futuro que ela pressupõe, poderia ter sido feita uma abordagem que apresentasse estas relações. Considerando, portanto, que ao se conhecer sobre o passado, é possível compreender melhor o presente, até mesmo para fazer escolhas diferentes das anteriores - na perspectiva de que pode haver similaridades entre situações e escolhas, mas não repetição do mesmo contexto - de acordo com a expectativa de futuro que se tem. A discussão torna-se, ainda, mais pertinente ao recordarmos que esta afirmação foi feita para o $3^{\circ}$ ano do Ensino Médio, quando a professora - mesmo sem conhecer os estudantes que estariam assistindo a sua aula por meio do Youtube - poderia no mínimo presumir quetivessem condições de uma reflexão mais elaborada sobre este sentido.

O conjunto de escolhas que cada docente faz decorre de vários elementos, desde seu habitus, com todos os valores, crenças, experiências e resultados vividos, que estão ali agregados; de seu conhecimento e interesse por alguns assuntos, mais que por outros - seja por leituras que fez, seja por interesse particular, seja por perceber maior sentido e significado, entre outros; das suas condições de trabalho, como número de turmas, de quais anos (o que implica conteúdos diferentes), carga horária, salário; pela finalidade que tem ou que concebe a respeito deste ensino, no caso de História, o que está relacionado à sua consciência histórica e à sua ética profissional. Poderíamos elencar diversas outras variáveis que podem impactar sobre estas escolhas, cujo conjunto, nem sempre totalmente consciente e intencional, resulta em uma dada prática. Por outro lado, os porquês destas escolhas ainda constituem um tema que necessita de maior investigação e aprofundamento, conforme indicam Gonçalves e Monteiro (2017), uma vez que as pesquisas voltadas a saberes docentes de professores/as de História, acabam por privilegiar o o que e o como fazem, e não essas outras indagações.

As questões levantadas como problemas também estão articuladas às atividades ou exercícios propostos, como veremos no próximo tópico.

\title{
ATIVIDADES PROPOSTAS NAS AULAS PARANÁ
}

Outro aspecto destacado nas análises realizadas pelos/as licenciandos/as refere-se aos encaminhamentos das atividades. Vale ressaltar que reconhecemos que, dada a ausência de interação entre estudantes e professores/as, nas Aulas Paraná, a dinâmica envolvendo a realização das atividades ficou

\footnotetext{
${ }^{10}$ Aula disponível em https://www.youtube.com/watch?v=vooqFMi207E\&list=PLnGI1S4A8rubSJkXdtgF9U7sOIjr2T0A\&index $=4$

Educação em Revista|Belo Horizonte |v.37|e32626|2021
} 
comprometida. No entanto, o destaque dado nos diários de campo se pautou no formato e em suas finalidades, e na forma pela qual elas se articulavam ou não com o percurso de aula.

Sobre a atividade relacionada ao conteúdo das Revoltas na Primeira República ${ }^{11}$, observou o acadêmico:

[...] a atividade que segue é bastante simplória, pede o nome do líder em uma questão de múltipla escolha, enquanto havia tantos temas, charges, e possibilidades diversas de gerar debates e reflexões. A outra já foi interessante, pois pediu para os alunos pesquisarem sobre o messianismo, trabalhando as habilidades de escrita e argumentação. (Licenciando 4)

abaixo:

Podemos notar que o licenciando está correto em sua apreciação, conforme observa-se

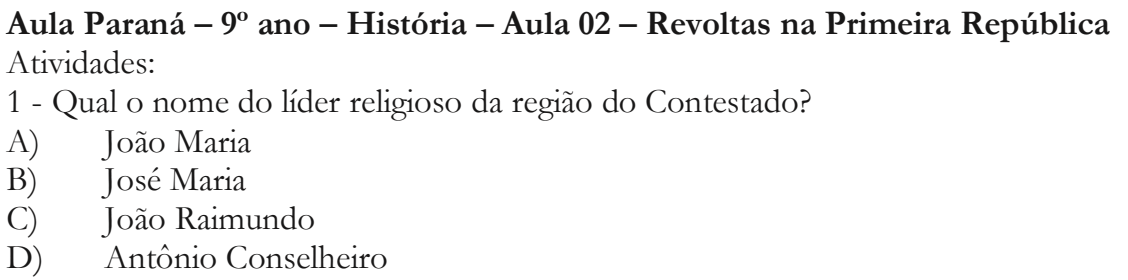

2 - Pesquise o significado do termo messianismo e associe o motivo pelo qual a revolta de Canudos pode ser considerada um movimento messiânico.

Fonte: Aula Paraná - Disponível em https://www.youtube.com/watch?v=ZU0L0yF80cA

É prudente registrar que o lugar da atividade em uma aula deve conectar-se justamente com a intenção didática, ou seja, ela não é realizada com um fim nela mesma, sendo necessário considerar que este percurso articula vários aspectos, como: a relação do sujeito com o conteúdo, a seleção de fontes feitas pelo/a professor/a, o desenvolvimento pedagógico da aula e, também, a atividade. Assim, construir o percurso de uma aula (conteúdo) denota um movimento que não acontece de forma fragmentada, ou ao menos não deveria. Por isso a observação de alguns/as acadêmicos/as que percebiam, em suas avaliações, a condução da aula de forma positiva, com uso de fontes e citação de textos historiográficos. Entretanto, no momento que se solicitava ao/à estudante, que estaria acompanhando aula, o registro dos seus argumentos sobre o conteúdo, a orientação do professor se pautava essencialmente em questões de registro de nomes, datas ou uma mera descrição, como fica evidente nas observações relatadas a seguir, sobre o conteúdo Tenentismo e Coluna Prestes ${ }^{12}$ :

Para fixar os temas apresentados, ele [o professor] faz alguns quizz bastante simples, que não fazem os alunos pensarem e construírem o conhecimento, apenas gravarem datas, nomes e acontecimentos. Em seguida, o mesmo tipo de construção de conhecimento acontece com a exposição do tema da Revolta dos 18 do Forte de Copacabana, sem fontes e seguido de um quizz bastante simples também. Já com a Coluna Prestes, o professor traz imagens e mapas, porém poderia ter trazido alguma fonte, pois o assunto é bastante rico, e as questões que seguem também não propiciam um espaço de reflexão, já que são perguntas bastante simplórias. (Licenciando 4)

Estes são alguns exemplos das atividades ${ }^{13}$ às quais o licenciando se refere:

1) O tenentismo era um movimento formado, principalmente, por:

\footnotetext{
${ }^{11}$ Esta aula está disponível em <https://www.youtube.com/watch?v=ZU0L0yF80cA>

12 Aula disponível em <https://www.youtube.com/watch?v=141NDF12PHg $>$.

13 Aula disponível em < https://www.youtube.com/watch?v=14lNDF12PHg $>$. 


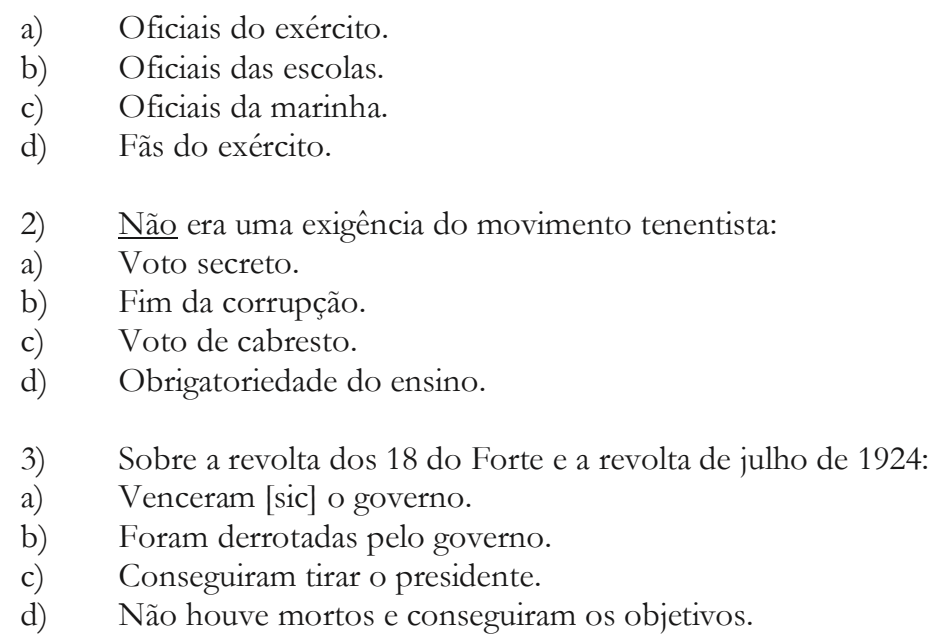

Fonte: Aula Paraná - Disponível em https://www.youtube.com/watch?v=141NDF12PHg

Ainda sobre as atividades, outros acadêmicos registraram o seguinte:

Por fim, talvez o aspecto mais negativo da aula tenham sido as questões, uma vez que foram rigidamente factualistas, sendo apenas uma delas dissertativa. (Licenciando 5)

Após 22 minutos de aula o professor traz um quizz, dando aos alunos três minutos para responder cada pergunta em seu caderno, seguindo por uma explicação sobre as respostas do quizz. Esse quizz se trata de questões de múltipla escolha e objetivas sobre assuntos abordados na aula. É a partir dessa aula que o professor começa a deixar uma contagem regressiva na tela mostrando aos alunos o tempo que teriam para responder essas questões. (Licenciando 6)

A professora também deixa questões de múltipla escolha dando um tempo para os alunos responderem. Apesar disso, o tempo de resolução de questões é muito curto. Logo em seguida, a professora cita questões dissertativas (algumas do livro didático), citando a página, mas sem dar tempo para os alunos responderem, apenas pedindo para os alunos anotarem para fazer depois. (Licenciando 6)

Os encaminhamentos relacionados às atividades demandaram debates significativos nos encontros virtuais entre os/as acadêmicos/as e nós, as professoras da disciplina, justamente porque desencadearam dúvidas e reflexões sobre o significado das chamadas atividades, ou sobre como conduzir esse processo. Como já dissemos, o fato de as Aulas Paraná serem realizadas sem a interação entre os sujeitos - professor e aluno - a dinâmica das atividades, bem como de toda aula, assumiu contornos diferentes e, no caso do debate com os/as licenciandos/a, a reflexão foi acerca de outras possibilidades para além daquelas que encontraram nas aulas on-line.

Quando ponderamos sobre as atividades a serem realizadas em aula, é necessário reconhecer o conjunto que a envolve: a forma pela qual o/a docente organizou a sua aula, a sua concepção de História, de ensino, de aprendizagem, ou seja, o que sustenta a própria prática de cada professor/a.

Como já mencionamos neste artigo, precisamos considerar neste processo a formação do/a docente, e mais que isso, seu habitus, que envolve sua consciência bistórica, que são, ambos, dinâmicos e constituídos ao longo de sua vida e trajetória, e que também contemplam uma ideia de ser docente, que vai sendo mediada na prática entre um ideal, e as condições objetivas de desenvolvimento de sua atividade profissional. A forma como a concepção de ensino e aprendizagem foi construída, indubitavelmente passa pela formação, no entanto sabemos que também é possível encontrar diferentes caminhos no decorrer da vida profissional.

Pagès Blanch (2004), em seu artigo Enseñar a enseñar História: la formación didáctica de los futuros profesores de História, afirma que a Didática da História pretende ser um ponto de referência, em que docentes possam ancorar suas reflexões sobre uma prática preocupada com o ensinar e aprender História 
e, desta forma, agreguem argumentos ou formas de pensar o ensino e a aprendizagem, ultrapassando a marca do conteudismo, muitas vezes matizada por uma racionalidade exclusivamente linear.

La Didáctica de las Ciencias Sociales y de la Historia se ocupa de estudiar las relaciones entre el profesor, el alumno y el saber escolar en el contexto de una clase y de un centro y en un momento histórico determinado, e investiga sus orígenes y tradiciones. Pretende elaborar conocimientos teórico-prácticos que permitan analizar y comprender qué ocurre cuando se enseña y se aprende Historia y Ciencias Sociales en contextos concretos y pensar alternativas para su enseñanza. (PAGÈS BLANCH, 2004, p.157)

O autor afirma, ainda, que a Didática da História deve se ocupar também do profissional que irá atuar com jovens e crianças, que, por meio de sua prática, poderá revelar a sua concepção e forma de compreender a História, assim como a sua maneira de se relacionar com o próprio conhecimento histórico.

Nesta direção, compreendemos que ao ensinar História há uma forma para tal e que esta, sem dúvida, envolve a trajetória pela qual o próprio sujeito professor construiu suas crenças e suas convicções acerca do que é ensinar História.

O debate advindo da transposição didática ${ }^{14}$ elucida aspectos presentes na forma como são organizadas as práticas das aulas comentadas pelos/as licenciandos/as. Há, nesta perspectiva, um movimento que toma o conteúdo "saber sábio" ou "saber escolar" como um dado resolvido. O/a estudante é "beneficiário/a" da modificação ocorrida com o conhecimento. Explicamos: a perspectiva da transposição didática empreende uma forma de pensar tomando prioritariamente o ensino - isto é, o conteúdo, a forma pela qual deve ser trabalhado. O/a professor/a é quem faz essas escolhas, ou seja, seleciona, organiza, recorre a fontes, sistematiza a "transposição". O/a estudante, sujeito desse processo, recebe essa modificação empreendida em relação ao conhecimento e por meio da ação docente. Chevallard (2005) propõe um tratamento didático do conteúdo a ser ensinado. Esse "processo didático" é o que caracteriza a transposição, ou seja, toma-se o conteúdo como ponto de referência para o tratamento didático, com vistas ao ensino.

Com as contribuições de Chevallard compreende-se que houve um exercício para se entender o ensino de História em direção a uma didática específica, na qual tomando-se como referência um dado conteúdo este passaria por uma "recriação, modificação ou adaptação", sendo "transformado" em um conteúdo de ensino, daí a expressão transposição didática.

Podemos considerar la existencia de una transposición didáctica, como proceso de conjunto, como situaciones de creaciones didácticas de objetos (de saber y de enseñanza a la vez) que se hacen "necesarias" por las exigencias del funcionamiento didáctico. (CHEVALLARD, 2005, p. 47)

Da mesma forma, Monteiro (2002), em suas reflexões mostra alguns pontos em relação à transposição didática, afirmando que essa abordagem tem recebido críticas no que diz respeito a uma ausência de explicação entre os saberes. Também pontua:

Outra restrição refere-se ao fato de que o autor, talvez por operar no campo da matemática que constitui um corpo de conhecimentos muito bem delimitados e sistematizados, refere-se exclusivamente ao saber acadêmico como única referência para a elaboração do saber ensinado. (MONTEIRO, 2002, p.83)

Ainda segundo Monteiro, Chevallard não leva em conta a "dimensão educativa" que, para a pesquisadora, é um aspecto fundamental para compreender o processo de uma transposição didática em relação ao saber escolar. As discussões sobre essa relação entre o saber sábio e o saber ensinado:

\footnotetext{
${ }^{14}$ Para saber mais ver a obra CHEVALLARD, Yves. La transposición didáctica: del saber sabio al saber enseñado. 3 ed. Buenos Aires: Aique, 2005. 
[...] pode fornecer um instrumental para a melhor compreensão dos processos de ensino, considerando as especificidades das diferentes disciplinas. O principal deles é a identificação das mudanças conceituais efetuadas durante o processo de transposição didática a partir das necessidades da "razão didática", ou seja, a lógica que exige que o saber ensinado, além do fato de atender a uma razão sociológica (demandas políticas e culturais), precisa ser possível de ser ensinado. (MONTEIRO, 2002, p. 85)

A importância dos debates sobre a transposição didática reside no fato de que esse conceito amplia as discussões em torno da relação entre o saber a ser ensinado e o saber ensinado, isto é, a distância que existe entre um chamado saber sábio, ou saber acadêmico e o saber necessário ou adequado ao ensino.

Nesta esteira, o olhar dos/as acadêmicos/as ao analisar as atividades revela a presença desta forma de pensar a aprendizagem, ou seja, o tratamento didático do conteúdo, por meio das atividades propostas, assume contornos da transposição. Reafirmamos que o formato on-line é limitador no que se refere à interação, no entanto, a construção das atividades apresentadas se aproxima da ideia de transpor conteúdo. A observação a seguir demonstra justamente a preocupação com o conteúdo: “Ao fim e ao cabo, se a apresentação da aula não foi muito instigante e nem se aproximou ao contexto dos alunos e suas consciências históricas, é importante ressaltar que o professor teve domínio do conteúdo e soube explicar bem o que se propôs." (Licenciando 5)

O exercício de observação, registro, análise das aulas e atividades gerou reflexões, preocupações por parte dos/as acadêmicos/as que, mesmo num cenário nada promissor, vislumbravam a possibilidade de adentrar no espaço físico da escola.

Diante do horizonte de possibilidades, por vezes foram destacados aspectos que já haviam sido objeto de discussão em disciplina que antecedeu a Prática de Docência, intitulada Metodologia do Ensino de História, que se pautou na construção de aulas de História que fossem ancoradas na ciência História, ou seja, no pressuposto de que a arquitetura de uma aula de História precisa ultrapassar a ideia de transpor ou mediar conteúdo, e contemplar um princípio metodológico fundamental que é a aprendizagem histórica, assim elucidada por Schmidt:

[...] a aprendizagem dever ser baseada em formas de pensamento histórico elaboradas pelo sujeito que aprende, e é com essas formas de pensamento, organicamente ligados ao ato de narrar, que o ensino de História precisa se relacionar. Segundo estes pressupostos, a aprendizagem histórica ocorreria quando o sujeito desenvolvesse, por meio da narrativa histórica, um sentido para a experiência histórica, de tal forma que ele poderia orientar a sua existência em relação a si mesmo e aos outros, no fluxo do tempo. Nesse sentido, a perspectiva da aprendizagem somente pode se orientar na direção de que o sujeito é construtor do seu conhecimento. (SCHMIDT, 2017, p.67)

Desta forma, defendemos que é condição sine qua non pensar um ensino de História que reconheça estudantes e docentes como sujeitos no processo e que assim contribua com o desafio de ensinar a pensar historicamente.

\section{CONSIDERAÇÕES FINAIS}

Considerando que as observações que aqui abordamos advêm de licenciandos/as em História em uma disciplina de Prática de Docência, podemos pensar sobre o que aprenderam e o que apreenderam a partir delas. Nas discussões realizadas com estes alunos, acerca dos diários de campo e das aulas assistidas, houve a percepção de que, por serem aulas disponibilizadas em um canal do Youtube, pela SEED, havia a expectativa de um cuidado maior no planejamento, no trato historiográfico e problematizador dos conteúdos, por parte dos/as professores/as, ou que haveria uma equipe assistindo as aulas, fazendo ajustes ou edições, antes de sua publicação. Afinal, eram e são os/as professores/as e a própria SEED que de certa forma estavam se expondo por meio deste material. Porém, esse tratamento das aulas não ocorreu.

Embora essas aulas estivessem disponíveis on-line, diversas questões identificadas nos diários de campo são comuns também quando a Prática de Docência é presencial - claro que com mais ou menos variações, conforme o/a professor/a que esteja sendo observado/a na escola -, evidenciando que 
apesar da mudança do suporte, na dimensão tecnológica, a base das práticas de cada docente é similar à da sala de aula presencial.

Outros elementos identificados foram algumas tendências predominantes nas aulas assistidas pelos/as licenciandos/as, mesmo quando se tratavam de turmas do Ensino Médio: a abordagem da História de forma cronológica, com poucas problematizações; o dilema quantidade de conteúdo x qualidade no aprofundamento e problematização dos temas; poucos momentos em que documentos trazidos eram questionados e tratados como fontes; além das atividades, em geral muito simples, objetivas, com questões voltadas para a fixação de datas, de nomes ou de informações mencionadas na explicação anterior do/a docente.

De um lado, podemos lembrar que todos/as fomos pegos/as de surpresa com a necessidade de aprendermos a lidar com tecnologia e aulas remotas, e no caso desses/as docentes, não foi diferente, o que pode nos ajudar a compreender porque a estrutura, os temas e a abordagem das aulas disponibilizadas continuaram semelhantes ao que já se realizava na sala de aula presencial, ainda que houvesse um preparo maior dos slides projetados (recurso poucas vezes disponível para docentes da rede pública em sala de aula presencial). Mais uma vez, podemos lembrar que o peso do babitus é muito grande sobre a prática, e esta não muda radicalmente, porque muda o suporte, ou porque o/a professor/a está sendo filmado. Como afirma Zavala (2017), todos somos bons, maus e medianos docentes, em distintos momentos de nossa trajetória, e em nossa atuação profissional. Elementos sob nosso controle, como a consciência acerca de nossa consciência histórica; o nível de conhecimento e de interesse a respeito de determinados temas e conteúdos, que impacta no sentido que atribuímos a eles, e consequentemente, na atenção que lhes damos; o planejamento que fazemos das aulas; e elementos fora de nosso controle, como o dilema quantidade x qualidade de conteúdos, que já mencionamos, ou o tempo de duração das aulas e os recursos disponíveis, por exemplo, impactam diretamente nas possibilidades e na qualidade de uma aula. Além disso, o que não abordamos aqui, mas que em uma aula presencial também é importante ressaltar, são os interesses e os sentidos atribuídos por parte dos/as estudantes em relação à escola, à disciplina e àquele conteúdo em particular, e que também não estão sob nosso controle, embora devamos considerar em nosso planejamento.

Ressaltamos a necessidade de refletir sobre aspectos que possibilitem tanto ao/à futuro/a professor/a, como ao/à docente que está diretamente envolvido/a com a sala de aula, vislumbrarem uma prática centrada nos processos de produção do conhecimento histórico, permeada pela problematização do ensino. Propomos, então, que esta prática tenha como referência a reflexão acerca do percurso de produção do conhecimento histórico, com vistas à formação de uma consciência bistórica.

As investigações que assumem a prática do/a professor/a como objeto de estudo possuem uma estreita relação com o processo de formação inicial; porém, esta formação não deve estar dissociada da dinâmica que caracteriza a escola, a sala de aula. Assim, a escola é o lócus onde essas análises podem certamente encontrar espaço e alcançar dimensões significativas, especificamente quanto ao/à professor/a de História, que:

[...] é o responsável por ensinar o aluno a captar e a valorizar a diversidade dos pontos de vista. Ao professor cabe ensinar o aluno a levantar problemas e a reintegrá-los num conjunto mais vasto de outros problemas, procurando transformar, em cada aula de História, temas em problemáticas (SCHMIDT, 1997, p. 57).

Para o debate que aqui apresentamos, o lócus foram as possibilidades reveladas pelas aulas online, com suas características peculiares, tanto para quem as organizou, como para quem as acompanhou. No entanto, mesmo esvaziadas da relação que somente acontece no interior da escola, estas aulas contribuíram para o debate fundamental que é pensar a relação ensino e aprendizagem, tão própria de quem assume que:

A literacia histórica tem como finalidade a aprendizagem para a formação da consciência histórica mais complexas. Isto significa que o ensino de história deve ter por objetivo a formação de uma consciência histórica que supere formas tradicionais e exemplares da consciência histórica, responsáveis pela consolidação de narrativas baseadas em organizações lineares do 
tempo, bem como as visões de que a história é a mestra da vida. Ao mesmo tempo, busca-se também evitar a formação de consciências críticas pautadas em narrativas que rompem com qualquer possibilidade de rever o passado. (SCHMIDT, 2017, p. 74)

As problematizações que os conceitos de habitus, de campo, de consciência histórica, de formação inicial, abordados neste artigo, permitem-nos fazer, foram mobilizadas para a construção de uma reflexão mais fundamentada destes/as licenciandos/as em relação ao papel do/a professor/a, da função do ensino de História na Educação Básica, bem como, de sua própria prática, posteriormente.

Consideramos, então, que apesar do momento, da experiência atípica, e das limitações envolvidas para a Prática de Docência, os resultados foram bastante satisfatórios, e a etapa inicial aqui tratada, de observação das Aulas Paraná, foi fundamental, pois trouxe elementos e uma base importante para as atividades que se seguiram na disciplina, propiciando aos/às licenciandos/as que as desenvolveram, subsídios, fundamentos e reflexões relevantes e que contemplam a finalidade da disciplina, acerca da docência e do ensino de História.

\section{REFERÊNCIAS}

BOURDIEU, Pierre. A economia das trocas lingüisticas: o que falar quer dizer. Prefácio Sergio Miceli. Tradução Sergio Miceli et al. São Paulo: Editora da Universidade de São Paulo, 1996. (Clássicos 4)

Coisas ditas. Tradução Cássia R. da Silveira; Denise M. Pegorim. São Paulo: Brasiliense, 2004.

BRASIL. Base Nacional Comum Curricular. Brasília: MEC, 2017. Disponível em http://basenacionalcomum.mec.gov.br/images/BNCC_EI_EF_110518_versaofinal_site.pdf Acesso em 20 de março de 2021.

BRASIL. Ministério da Educação. Resolução CNE/CP n. 2, de 20 de dezembro. Define as Diretrizes Curriculares Nacionais para a Formação Inicial de Professores para a Educação Básica e institui a Base Nacional Comum para a Formação Inicial de Professores da Educação Básica (BNC-Formação). Brasília, 2019. Disponível em: http:/ / portal.mec.gov.br/index.php?option=com_docman\&view=download\&alias=133091-pcp02219-3\&category_slug=dezembro-2019-pdf\&Itemid=30192 Acesso em 20 de março de 2021.

CERRI, Luis F. O ensino de História como objeto de pesquisa e de ação educativa: a atualidade de uma Associação Brasileira de Ensino de História. HHMagaz̧ine - Humanidades em Rede, 21/12/2018. Disponível em https://hhmagazine.com.br/o-ensino-de-historia-como-objeto-de-pesquisa-e-de-acao-educativa-aatualidade-de-uma-associacao-brasileira-de-ensino-de-historia/. Acesso em 20 de março de 2021.

CHEVALLARD, Yves. La transposición didáctica: del saber sabio al saber enseñado. 3 ed. Buenos Aires: Aique, 2005.

GONÇALVES, Nadia G.. Para além da reprodução: contribuições de Pierre Bourdieu para uma reflexão sobre formação de professores para o ensino de História. EntreVer - Revista das Licenciaturas, v. 2, p. 153171, 2012.

GONÇALVES, Nadia G. e MONTEIRO, Ana M. F. C. Saberes e práticas docentes e ensino de História: temas, conceitos e referenciais (1970-2014). Educação em Revista (UFMG), Belo Horizonte , v. 33, e156257, $2017 . \quad$ Disponível em $<$ http:/ /www.scielo.br/scielo.php?script=sci_arttext\&pid=S010246982017000100112\&lng=en\&nrm=iso > . Acesso em 20 de março de 2021. 
LOURENCETTI, Gisela C. e MIZUKAMI, Maria G. N. Dilemas de professoras em práticas cotidianas. In: MIZUKAMI, Maria G.N. e REALI, Aline M.M.R. (orgs.) Aprendizagem profissional da docência: saberes, contextos e práticas. São Carlos: Ed.UFSCar, 2002, p.49-69.

MACEDO, Renata M. Direito ou privilégio? Desigualdades digitais, pandemia e os desafios de uma escola pública. Estudos Históricos (Rio de Janeiro) [online]. 2021, v. 34, n. 73 [Acessado 13 Julho 2021] , pp. 262-280. Disponível em: <https://doi.org/10.1590/S2178-149420210203>.

MARTINS, Maria C. A história prescrita e disciplinada nos curriculos escolares: quem legitima esses saberes? Bragança Paulista: EDUSF, 2002.

MESQUITA, Ilka M. D. Memórias/identidades em relação ao ensino e formação de professores de história: diálogos com fóruns acadêmicos nacionais. 2008. 269 f. (Doutorado em Educação) - Programa de Pós-Graduação em Educação, Universidade Estadual de Campinas, Campinas, SP. Disponível em: http://repositorio.unicamp.br/bitstream/REPOSIP/252062/1/Mesquita_IlkaMigliode_D.pdf. Acesso em 20 de março de 2021.

MONTEIRO, Ana Maria F. da C. e PENNA, Fernando de A. Ensino de História: saberes em lugar de fronteira. Educaşão \& Realidade, v.36, n.1, p. 191-211, jan-abr. 2011. Disponível em https://seer.ufrgs.br/educacaoerealidade/article/view/15080/11518 Acesso em 20 de março de 2021.

MONTEIRO, Ana Maria F. da C. Ensino de História: entre saberes e práticas. Rio de Janeiro, 2002. 256 f. (Tese de Doutorado) Pontifícia Universidade Católica do Rio de Janeiro. PUC/Rio.

MORENO, Jean Carlos. A história na Base Nacional Comum Curricular. Déjà vu e novos dilemas no século XXI. História \& Ensino. Londrina, v. 22, n. 1, p. 07 - 27, jan./ jun. 2016. Disponível em http://www.uel.br/revistas/uel/index.php/histensino/article/view/26158/19188 Acesso em 20 de março de 2021.

OLIVEIRA, Odisséa B. O diário na prática de ensino. Seminário do 12 COLE, 2009. Disponível em http://alb.com.br/arquivo-morto/edicoes_anteriores/anais16/sem12pdf/sm12ss09_06.pdf Acesso em 20 de março de 2021.

PAGÈS BLANCH, Joan. Enseñar a enseñar Historia: la formación didáctica de los futuros profesores de historia. In: HERNÁNDEZ, José Antonio Gómez e MARIN, M. Encarnación Nicolás.Miradas a la historia reflexiones historiográficas en recuerdo de Miguel Rodríguez. Murcia: Universidad de Murcia, Vicerrectorado de Extensión Cultural y Proyección Universitaria 2004, p. 155-178.

RÜSEN, Jörn. Didática da História: passado, presente e perspectivas a partir do caso alemão. In: SCHMIDT, M. A.; BARCA, I.; MARTINS, E. R. (Orgs.). Jörm Rüsen e o ensino de história. Curitiba: EdUFPR, 2010, p. 23-40.

SCHMIDT, Maria A. Jörn Rüsen e sua contribuição para a didática da História. In: Dossiê: sentido e relevância da História no mundo contemporâneo. Intelligere, Revista de História Intelectual. vol. 3, no 2, out. 2017. Disponível em: http://www.revistas.usp.br/revistaintelligere/article/view/127291/136217 Acesso em 20 de março de 2021.

SCHMIDT, Maria A. A formação do professor de História e o cotidiano da sala de aula. In: BITTENCOURT, Circe (org.) O saber histórico na sala de aula. São Paulo: Contexto, 1997. p.54-66.

UFPR. PROGRAD. Relatório Geral - Ensino Remoto Emergencial. Curitiba: PROGRAD-UFPR, 2020. Disponível em http://www.prograd.ufpr.br/portal/wp-content/uploads/2020/10/Periodo-Especial- 
Junho-Outubro-2020_ERE1_Pesquisa_Relatorio-Final-

1.pdf?fbclid=IwAR2kcHfJuNmpdRTyc3B_qgGTsCgyWlFUTnkikGG6mI0gTAPsALA-fBtedGA

URBAN, Ana Claudia. Didática da História: contribuições para a formação de professores. Curitiba: Juruá, 2011.

ZAVALA, Ana. En torno a los discursos acerca de la formación profesional docente. Cadernos de Pesquisa, São Paulo, v. 47, n. 164, pág. 716-739, junho de 2017. Disponível em $<$ http://www.scielo.br/scielo.php?script=sci_arttext\&pid=S0100-

$15742017000200015 \& \operatorname{lng}=$ en\&nrm=iso $>$. Acesso em 20 de março de 2021.

Submetido: $22 / 03 / 2021$

Aprovado: 11/09/2021 